\title{
DEFENSORIA PÚBLICA DA UNIÁO EM DADOS: UM BALANÇO DE UMA PESQUISA INSTITUCIONAL (2010-2016)
}

\author{
FEDERAL PUBLIC DEFENDER'S OFFICE ON DATA: A BALANCE OF INSTITUTIONAL \\ RESEARCH (2010-2016)
}

\begin{abstract}
Ana Luiza Lopes Koech
Graduada em Direito pela UFSM

Leonardo do Amaral Pedrete

Doutorando em Antropologia pela UFRGS.

Mestre em Sociologia pelo Iuperj,

Sociólogo da Defensoria Pública da União em Santa Maria-RS

Igor Nielson Medeiros Schirmer Doutorando em Ciência Politica pela UFRGS. Mestre em Ciências Sociais pela UFSM
\end{abstract}

\section{INTRODUÇÁO}

No contexto mundial e nacional de expansão das instituiçóes jurídicas e de judicialização das relaçóes sociais ${ }^{1}$, impóe-se à Defensoria Pública da União uma atuação transparente e proativa no exercício da assistência jurídica (e não apenas judicial) integral e gratuita. Em que pesem dificuldades estruturais e institucionais, as demandas por acesso à justiça no Brasil encontram no sistema brasileiro de defensoria pública um potencial promissor. Traços como a defesa de interesses difusos e coletivos, a assistência jurídica gratuita (judicial e extrajudicial) e a educação voltada à promoção de direitos são atribuiçốes institucionais que fazem a Defensoria Pública abranger distintos níveis do processo de construção da cidadania e perpassar as diferentes ondas de acesso à justiça ${ }^{2}$.

No entanto, muito pouco se sabe sobre aqueles que recebem o atendimento das instituiçóes estatais destinadas à prestação de assistência jurídica integral e gratuita no Brasil. Visando contribuir para o suprimento de tal lacuna, o objetivo central do projeto "DPU Santa Maria em Dados" é implantar a produção e a análise de dados sobre a atuação da Defensoria Pública da União de Santa Maria (DPU-SM). Tal propósito se alinha a diversas diretrizes estratégicas da instituição, uma vez que o conhecimento rigoroso e sistemático da atuação da Defensoria e de seus assistidos é fundamental para metas como o direcionamento de

\footnotetext{
$1 \quad$ Cf. TATE, VALLINDER, 1995; WERNECK VIANNA, 1999.

$2 \quad$ Cf. SANTOS, 2007; SADEK, 2008.
} 
políticas institucionais à população abaixo da linha da miséria, a promoçẫo da difusão e da conscientização dos direitos humanos, da cidadania e do ordenamento jurídico e a atuação, de forma proativa, junto à sociedade.

Este artigo tem por objetivo expor os resultados de mais de seis anos de implementação deste projeto de pesquisa institucional, cujos levantamentos de dados lançam novos olhares sobre as relaçōes entre acesso à justiça e a efetividade de instituiçôes públicas. Especificamente, serão analisados aqui resultados que sugerem tendências e padrōes peculiares referentes à mobilização do sistema de justiça federal em nível local. Também serão detalhados aspectos fundamentais do fluxo de alguns dos pedidos mais frequentemente recebidos pela instituição ao longo dos anos, como os de medicamentos, benefício de prestação continuada e cirurgia. Espera-se, com este trabalho, reafirmar que a produção de conhecimento sobre as demandas e os demandantes de assistência jurídica é indispensável para a democratização do acesso à justiça.

Afinal, informaçóes públicas transparentes e qualificadas possibilitam o controle social sobre a tomada de decisóes e permitem resultados mais efetivos, eficazes e eficientes no curso de políticas públicas. Sobretudo no âmbito da Defensoria Pública da União, o exercício da accountability ${ }^{3}$ está diretamente imbricado com a busca por uma crescente responsividade $^{4} \mathrm{da}$ instituição. Em outras palavras, a abertura institucional às demandas sociais está intimamente relacionada à responsabilidade, à obrigação e à responsabilização de uma instituição, ou de quem ocupa um cargo público, no sentido de prestar informaçóes e justificaçóes submetidas a controle interno ou externo. Por tais razóes, o mapeamento das demandas e o delineamento do perfil dos assistidos pela instituição se fazem necessários.

Dessa forma, a pesquisa "DPU Santa Maria em Dados" - cujos resultados são aqui apresentados - se vincula à missão institucional de "garantir aos necessitados o conhecimento e a defesa de seus direitos" ", "promover a difusão e a conscientização dos direitos humanos, da cidadania e do ordenamento jurídico"6, e, em última instância, de democratizar

\footnotetext{
Remete-se aqui ao conceito de accountability, que envolve a responsabilidade, a obrigação e a responsabilização de uma instituição ou quem ocupa um cargo em prestar contas - informaçóes e justificaçôes submetidas a controle interno ou externo (PINHO e SACRAMENTO, 2009). Como mostra Campos, accountability e democracia sáo interdependentes, uma vez que implicam a possibilidade de controle da coisa pública pela cidadania, a descentralização e a transparência da Administraçãao Pública, e a substituição de valores tradicionais (clientelismo, paternalismo, patrimonialismo e personalismo) pela supremacia do interesse coletivo (CAMPOS, 1990).

4 A permeabilidade das instituições jurídicas às demandas sociais, novas ou antigas, com a preservação da integridade do direito é a característica do Direito Responsivo, conforme formulação de Nonet e Selznick (2010). "Tem-se, portanto, que da responsividade do direito náo se origina um direito alternativo direcionado à ruptura com a integridade do direito, mas um processo contínuo de autocorreção, acompanhando a mudança social e as novas expectativas de direitos dela emergentes. Tem-se, ainda, dado que a responsividade implica a expansáo da malha do sistema institucional do direito — juizados especiais, class actions —, que a sua dimensão de "abertura" se apresenta como um canal permanente para a difusão e a socialização do direito no corpo social. Sobretudo para sua criaçáo, sem perda de uma integridade que se institua à base de princípios de justiça e de igual-liberdade" (WERNECK VIANNA, L., 2005).
}

$5 \quad$ Cf BRASIL (2012, p.19).

6 Cf. art. $4^{\circ}$, III, da Lei Complementar no 80/1994, alterada pela Lei Complementar n 132/2009. 
o acesso à justiça. Ao lado de princípios institucionais como responsabilidade social, humanização, profissionalismo, qualidade e eficiência, o projeto se orienta sobretudo pelo princípio da transparência, no intuito de "dar máxima publicidade e visibilidade aos atos, processos e políticas institucionais" ". Assim, o diagnóstico da atuação da DPU contribui efetivamente para a missão de "garantir aos necessitados o conhecimento e a defesa de seus direitos" conforme a visão de firmar-se como "instrumento de transformação social"8 - à medida que figura como um aporte reflexivo fundamental para a própria realização de tais diretrizes normativas.

\section{PANORAMA GERAL DO “DPU SM EM DADOS”}

Quais são as maiores demandas que a Defensoria Pública da União (DPU) em Santa Maria ${ }^{9}$ efetivamente recebe? Quem são as pessoas que recebem a assistência jurídica dessa instituição? Quais são as pretensóes mais frequentemente recebidas pelo núcleo e quais os ramos jurídicos mais acionados? Como tem evoluído o número de atendimentos iniciais, nos últimos meses e anos? De que maneira tais variaçóes se refletem nas diretrizes de atuação da instituição? Como os resultados obtidos podem possibilitar avanços na prestação da assistência jurídica integral e gratuita à população socialmente vulnerável? Essas foram as questóes que nortearam e norteiam a pesquisa.

Em virtude do propósito descritivo da pesquisa e das dimensóes do universo dos atendimentos iniciais, recorreu-se a levantamentos ou surveys do tipo populacional ou censitário. As informaçóes que resultam no perfil dos assistidos são derivadas de duas estratégias de coleta. Como o próprio Sistema de Informaçóes Simultâneas da Defensoria Pública da União (SISDPU) dispõe de formulários socioeconômicos fixos, alguns dados de categorias básicas (renda familiar, escolaridade, ocupação e número de pessoas na residência) são colhidos a partir do acesso aos Processos de Assistência Jurídica (PAJs) de todos os atendimentos iniciais ${ }^{10}$. Por sua vez, as demais categorias são coletadas a partir de entrevistas

\footnotetext{
$7 \quad$ Cf. BRASIL (2012, p.20).

$8 \quad$ Ibidem, p.19.

$9 \quad$ O núcleo de Santa Maria da Defensoria Pública da União atende aos moradores dos 23 municípios que compóem a circunscrição da Justiça Federal sediada em Santa Maria (Agudo, Dilermando de Aguiar, Dona Francisca, Faxinal do Soturno, Formigueiro, Itaara, Ivorá, Jari, Júlio de Castilhos, Mata, Nova Palma, Pinhal Grande, Quevedos, Restinga Seca, Santa Margarida do Sul, Santa Maria, São João do Polêsine, São Martinho da Serra, São Pedro do Sul, São Sepé, Silveira Martins, Toropi e Vila Nova do Sul). Segundo o Censo 2010 do Instituto Brasileiro de Geografia e Estatística (IBGE), os moradores de tais municípios totalizam uma população de 420.683 pessoas (3,93\% do total do Rio Grande do Sul), dos quais 81\% habitam a zona urbana e $19 \%$, a rural; a população feminina abrange $51,6 \%$ do total, sendo portanto em $48,4 \%$ a parcela do sexo masculino.

10 Convém esclarecer que as definições aplicadas para categorias como "cor" e "religiāo" obedeceram aos critérios da técnica de coleta de dados da autodeclaração, amplamente utilizada pelo IBGE.
} 
socioeconômicas, realizadas em todos os atendimentos iniciais presenciais ${ }^{11}$.

Assim como o eixo do perfil dos assistidos, o mapeamento das demandas é operacionalizado mediante a criação de um banco de dados próprio atualizado permanentemente, tendo como única fonte o SISDPU. Um a um, todos os atendimentos iniciais produzidos durante os anos da pesquisa foram consultados, não sendo realizado qualquer procedimento amostral. ${ }^{12}$ A consulta a cada uma das narrativas geradas nos atendimentos iniciais tem por objetivo analisar a demanda do assistido. Para evitar distorçôes estatísticas, optou-se por considerar-se apenas a demanda trazida em nome do assistido ${ }^{13}$.

Os ramos jurídicos foram divididos nas categorias "Previdenciário", "Cível”, "Saúde“, "Penal", "Penal-Militar" e "Cíveis Outras" (na qual foram incluídas categorias com frequência inferior a 5\%, como "Administrativo", "Trabalhista”, "Tributário" e "Eleitoral”). ${ }^{14}$ Não obstante, quando da coleta de dados, tais categorias permanecem separadas, possibilitando futuras análises mais específicas. A separação de categorias como "Saúde" de "Cível" tem a mesma justificativa, somada ao fato de apresentar uma proporção elevada.

\subsection{Perfil dos assistidos}

O "DPU SM em Dados" produziu dados gerais sobre o perfil dos assistidos da DPU em

\footnotetext{
11 Por uma série de razóes, não é possível a realização de entrevistas com os assistidos em todos os atendimentos iniciais. O exemplo de casos de pessoas internadas em estado de coma, por razóes óbvias, mostra que não é possível entrevistar diretamente a totalidade dos assistidos. Nestes casos e em situaçóes similares, a entrevista é feita com o familiar ou representante legal que veio ao atendimento. Há casos, entretanto, em que a Defensoria presta assistência jurídica a pessoas que nunca receberam orientaçáo a partir de uma visita à unidade, como nos casos de intimação por carta precatória e de réus militares presos. Nesses casos, as entrevistas socioeconômicas não são viáveis. Dado que algumas entrevistas não são realizadas diretamente com o assistido, mas sim com alguém atendido em seu nome, ao longo da apresentaçáo de resultados, optamos por diferenciar os termos "assistidos" e "atendidos".

12 Para fins estatísticos, foram considerados inválidos e descartados todos os registros que não configuraram atendimentos iniciais reais, tais os decorrentes de duplicações e testes. Além disso, é importante assinalar que o núcleo adota a diretriz de que sejam registrados no sistema todos os atendimentos iniciais realizados presencialmente. Dessa forma, os atendimentos telefônicos prestados a pessoas que não são assistidas pela DPU não passam pelo processo de coleta e mapeamento de dados. Ademais, se um assistido provoca o desarquivamento de um pedido anteriormente realizado, o seu novo atendimento não é contabilizado novamente. Caso uma pessoa traga mais de uma demanda jurídica (medicamentos e BPC, por exemplo), cada uma delas gera um PAJ. Portanto, um mesmo PAJ pode atender a mais de uma pessoa, tal como ocorre em processos penais com vários réus assistidos pela DPU. Por essas razóes, o número de assistidos e o de atendimentos iniciais não coincide, em geral. As estatísticas produzidas neste estudo consideram apenas os atendimentos iniciais presenciais (encontram-se excluídos, portanto, modalidades tais como: atendimentos de retorno, audiências etc.).

13 Portanto, quando a narrativa deu conta de que também foram prestadas informaçôes sobre outras matérias ou sobre demandas de outras pessoas, apenas a pretensão principal do assistido foi contabilizada nesta etapa de análise.

14 Para evitar controvérsias quanto à natureza jurídica das demandas, optou-se por privilegiar a vara ou tribunal de processamento como critério distintivo. Portanto, pedidos de levantamento de FGTS são enquadrados como cíveis, enquanto questóes relativas ao recolhimento do FGTS pelo empregador são classificadas como trabalhistas. Pelo mesmo critério, pedidos de amparo assistencial (ou BPC-BPC) são incluídos na categoria "previdenciário".
} 
Santa Maria até 2016. Os resultados dão conta de que, nos atendimentos iniciais registrados no referido ano, os homens passaram a compor a maioria $(54,6 \%)$ dos assistidos. Embora em atendimentos relativos a cirurgias e medicamentos as mulheres constituam maioria $(52,5 \%$ e $54,2 \%$, respectivamente), o aumento no número de registros de atendimentos para execução penal (no qual a parcela masculina atinge 94,5\% dos PAJs) é suficiente para explicar a inversão do que ocorria até 2014, quando as mulheres compunham a maioria dos assistidos (representando um total de 57,4\% dos atendimentos).

Quanto ao perfil etário do público da DPU, verificou-se que aproximadamente dois terços dos assistidos são adultos de meia idade ou idosos, dado que 63\% têm mais de 40 anos. A idade média verificada foi de 46,5 anos. Dentre aquelas mais frequentes, algumas demandas registraram médias de idade ligeiramente acima da média geral, como nos pedidos relativos a aposentadoria (66,6 anos) e cirurgia (52,8 anos), com os assistidos envolvidos em execuçóes penais destacando-se pela baixa idade média (34,3 anos).

Quanto à renda declarada pelos assistidos, a renda familiar média $(\mathrm{R} \$ 1.793,76)$ e a renda per capita média $(\mathrm{R} \$ 729,10)$ não podem ser tomadas como dados absolutos: o corte por faixas de renda familiar média apresentou grande heterogeneidade quanto à renda dos assistidos. Em salários mínimos (s.m.), as categorias com maiores frequências foram "de 1 a 2 s.m." (37,4\%), "de 2 a 3 s.m.” (27,1\%) e "até 1 s.m." (16,2\%). Por outro lado, chama a atenção a proporção de assistidos com renda superior a três salários mínimos (18,3\%). No entanto, ressalte-se que, em pesquisas anteriores, o percentual de assistidos que informaram renda acima do limite de triagem da DPU foi ainda superior (20,4\%, em 2012; $28,3 \%$ em 2013). A heterogeneidade no perfil de renda é ainda mais flagrante quando se considera demandas diferentes, visto que os atendimentos penais-militares e previdenciários se destacam com altos percentuais de assistidos com renda familiar inferior a um salário mínimo (30,7\%, em PAJs previdenciários e 33,3\%, em PAJs penais-militares bastante acima da média geral, de 16,5\%).

Dados mais aprofundados sobre o perfil dos assistidos foram produzidos em 2014 acerca do ano anterior. Quase metade dos assistidos (43,6\%) encontrava-se desempregada. Mais de 1 em cada 4 (26\%) são aposentados e apenas 14,6\% participavam da economia formal. Em 2012, os desempregados, aposentados e assistidos em economia formal somavam $33,2 \%, 24,9 \%$ e 26,6\%, respectivamente. Portanto, houve significativo aumento de desempregados e notável redução na proporção de trabalhadores regulamentados dentre o total de assistidos.

Mais da metade dos assistidos (55,4\%) declararam possuir gastos extraordinários com saúde; e apenas uma minoria (5,2\%) paga pensão alimentícia. Quase a metade $(48,3 \%)$ dos assistidos não possui ensino fundamental completo e mais de 6 em cada $10(64,6 \%$ dos assistidos) não possui o ensino médio completo. No ano anterior, tais grupos somavam $42,4 \%$ e $63,8 \%$. Em relação a 2012, destacaram-se os aumentos nas proporçóes de assistidos com ensino fundamental incompleto (que passaram de 37,8\% para 42,4\%) e de assistidos analfabetos (de 4,6\% para 5,9\%). Quanto à religião, a maior parcela dos assistidos se declarou católica $(67,5 \%)$, bastante à frente de evangélicos $(20,5 \%)$ e pessoas sem religião (em sentido estrito, 4,6\%; ou 7,9\% englobando-se ateus e agnósticos). Quanto ao tipo de moradia, 68,7\% moravam em imóvel próprio e 19,8\%, em imóvel alugado. 
A esmagadora maioria $(89,6 \%)$ nunca havia sido atendida antes pela DPU e $7,4 \%$ receberam atendimento por meio do projeto "DPU Itinerante" 15 . A maior parte dos assistidos (40,4\%) tomou conhecimento do atendimento da DPU a partir de amigos, parentes ou vizinhos. A seguir, "Fórum/nomeação judicial" (17,6\%), "Jornal/TV/Rádio/Internet" (8,0\%), "Defensoria Pública do Estado" (6,3\%) e "Material de Divulgação da DPU" $(5,4 \%)$ foram as fontes de indicação mais citadas pelos entrevistados.

Em 2014, a pesquisa também buscou identificar indicadores de vulnerabilidade social. Os mais citados foram a participação em programa social do governo federal (17,2\%), a presença de morador analfabeto com 15 anos ou mais na residência $(5,2 \%)$, residência sem rede de esgoto, pluvial ou fossa (4,3\%) e a renda familiar de até R\$70,00 per capita (2,9\%, abaixo dos 4,8\% de 2013). Este último indicador passou a 5,2\% em 2016, indicando um discreto aumento na cobertura do atendimento em relação à população em extrema pobreza.

\subsection{Mapeamento de demandas}

De 2010 a 2016, o projeto “DPU SM em Dados" registrou importantes variaçóes quanto às demandas recebidas pelo núcleo de Santa Maria da Defensoria Pública da União. Nesse período, houve $28,4 \%$ de aumento no número de atendimentos iniciais (1331, em 2016). Por outro lado, considerando-se o ano de maior frequência de abertura de PAJs, 2014 (com 1633 AI), observa-se, nos últimos dois anos, uma retração de 18,5\% no total de AI.

Assim como nos últimos anos, as matérias predominantes nos atendimentos iniciais em 2016 foram, respectivamente: "Saúde" (34,7\%), "Previdenciário" (25,2\%) e "Cíveis Outras" (20,5\%). Ou seja, ao menos 3 em cada 4 atendimentos iniciais foram cíveis ou previdenciários. Além disso, ao menos 1 em cada 3 foram casos cíveis relativos à saúde. Menos de $20 \%$ dos atendimentos se referem a matérias penais ou penais-militares (que contam 10,6\% e $9 \%$ dos AI, respectivamente).

\footnotetext{
15 Implementado há mais de seis anos, o projeto "DPU Itinerante" tem como principal objetivo promover a interiorização da instituição DPU, buscando universalizar o acesso à Justiça e difundir o conhecimento sobre a Defensoria, promovendo direitos e cidadania à população. Até 2009, receberam ações de atendimento ao público cidades como São Sepé, Dilermando de Aguiar, Toropi, Ivorá, Restinga Seca, Faxinal do Soturno, Júlio de Castilhos, Formigueiro, Mata e São Martinho da Serra. Em 2010, foram realizadas 02 (duas) visitas a São Sepé. A partir de 2011, o núcleo passou a adotar como meta intermediária da unidade a ampliação das visitas de atendimento a Municípios da Subseção Judiciária de Santa Maria, RS, incorporandoas ao planejamento anual de açóes especiais, coordenadas pelo Setor de Sociologia. A escolha das cidades tem obedecido aos seguintes critérios: localidades com maiores demandas fora de Santa Maria, distância geográfica e índice de pobreza do Município (conforme dados do IBGE). Para além de várias localidades já citadas, as mais de 100 (cem) açóes realizadas no referido período chegaram ainda aos municípios de Itaara, São Pedro do Sul, Vila Nova do Sul e Agudo. Assim, pode-se dizer que quase dois terços (catorze de vinte e três) dos Municípios da Subseção Judiciária de Santa Maria na Justiça Federal já receberam açóes de atendimento in loco. Em 2016, a unidade implementou o projeto "Defensoria para Todos", destinado a descentralizar o planejamento e a execução de açôes voltadas à ampliação da abrangência de atuação DPU. Em 2017, o planejamento de açóes itinerantes contempla visitas a 13 municípios (Formigueiro, Vila Nova do Sul, Santa Margarida do Sul, Mata, São Pedro do Sul, Dilermando de Aguiar, Faxinal do Soturno, Nova Palma, Pinhal Grande, Júlio de Castilhos, Agudo, Restinga Seca e São Sepé).
} 
Tabela 1 - Dados gerais sobre as demandas de saúde (2010-2016)

\begin{tabular}{c|ccccc} 
& 2011 & 2012 & 2013 & 2014 & 2015 \\
\hline Atendimentos iniciais & 290 & 334 & 399 & 434 & 383 \\
Posiçăo no ranking de atendimentos & $3^{\circ}$ & $2^{\circ}$ & $2^{\circ}$ & $1^{\circ}$ & $1^{\circ}$ \\
Percentual em relaçáo ao total & $21,5 \%$ & $25,1 \%$ & $24,7 \%$ & $26,6 \%$ & $29,7 \%$
\end{tabular}

As pretensões mais frequentes, em 2016, envolvem respectivamente: cirurgia, auxíliodoença, medicamento, execução penal e BPC. De 2011 a 2016, o número de atendimentos iniciais de saúde chegou ao topo do ranking das matérias mais acionadas, ao ultrapassar casos previdenciários e outros casos cíveis. Embora as pessoas que acessam a DPU-SM levem questôes relacionadas a pedidos de consulta especializada, exames, tratamentos, internações, equipamentos e materiais de saúde, dois pedidos são por si só responsáveis pela maioria das demandas dessa área: os pedidos de realizaçáo de cirurgia e os pedidos de fornecimento de medicamentos - que representaram, juntos, dois terços dos atendimentos relativos a saúde em 2016.

Especialmente de 2013 em diante, os pedidos de cirurgia passaram a despontar como a pretensão mais frequente. Comparando-se os anos de 2011 e 2016, o número de AI relativos a medicamentos caiu quase que pela metade (reduzindo de 202 para $118 \mathrm{AI}$ ); de outro lado, o número de PAJs referentes a cirurgias é quase seis vez maior hoje (passando de 32 para $181 \mathrm{AI}$ ). Os pedidos de auxílio-doença e BPC observaram grande crescimento no número de atendimentos iniciais de 2011 até 2013; no entanto, em 2016, revelaram tendência de retorno a patamares parecidos com os obtidos em 2011. Com efeito, considerando-se respectivamente os anos de 2011, 2013 e 2016, o número de PAJs de auxílio-doença $(109 ; 150 ; 128)$ variou de forma algo semelhante ao número de PAJs de $\operatorname{BPC}(63 ; 112 ; 60)$.

Em verdade, a despeito de a categorização jurídica variar entre "cível-saúde" (casos de cirurgias e medicamentos) e "previdenciário" (casos de auxílio-doença, BPC e aposentadoria), boa parte dos casos enquadrados nas categorias mais frequentes se referem a demandas que tem como causa a condição de saúde da pessoa. Afinal, o auxílio-doença é um direito do segurado que perde a capacidade para o trabalho, o BPC contempla pessoas com deficiência e incapacidade de prover o próprio sustento e, dentre os tipos de aposentadoria está a aposentadoria por invalidez. Assim, não é desarrazoado estimar que metade dos atendimentos da DPU-SM tenham a saúde como fator de mobilizaçáo do sistema de justiça.

É possível aventar algumas hipóteses para a flutuação das demandas. Em Santa Maria, nos últimos anos tem se agravado a incapacidade de o SUS dar conta das indicaçóes de cirurgia, especialmente das cirurgias eletivas traumato-ortopédicas, o que trouxe reflexos sobre a judicializaçáo de tais demandas. Em sentido inverso, a inclusão de novos medicamentos na lista de fornecimento do estado do RS contribuiu decisivamente para uma menor judicialização de tais demandas. 


\section{PESQUISAS ESPECÍFICAS}

\subsection{A demanda por medicamentos na DPU-SM em 2011}

Embora não haja um consenso entre fontes de dados, o Rio Grande do Sul seria o estado líder no ranking de processos de pedidos de medicamentos no país, sendo que Santa Maria seria a cidade com maior número de processos judiciais deste tipo no Estado, à frente mesmo de Porto Alegre. Somente em 2014, o custo financeiro da $4^{a}$ Coordenadoria Regional de Saúde, para compra de medicamentos pela via judicial, girou em torno de $\mathrm{R} \$$ 8 milhóes ${ }^{16}$. Ao tematizarem a judicialização da saúde para casos de medicamentos, uma série de autores ${ }^{17}$ evidenciam a relevância da assistência jurídica gratuita.

Levantamento específico realizado sobre o fluxo processual das demandas de medicamentos na DPU-SM, em 2011, prestou informaçōes bastante relevantes. Por vezes, surpreendentes. Verificou-se que apenas metade dos atendimentos iniciais se converteram em processos judiciais. Esse dado é suficiente para atestar que a judicialização pode ser apenas uma fração do trabalho de uma instituição jurídica como a DPU, embora provavelmente seja a mais divulgada dentro e fora dela.

Houve significativa taxa de desistência pré-processual (28\%), fato possivelmente motivado por razóes como: obtenção do medicamento diretamente na via administrativa, no curso do atendimento pré-processual da DPU; dificuldade em obtençáo dos documentos necessários (tais como laudos médicos e negativas administrativas); e desistência expressa do assistido, por razóes diversas, tendo havido ou não a obtenção do medicamento.

Vale dizer que todos os pedidos judiciais de medicamentos ensejaram análise prévia ao mérito quanto à urgência e verossimilhança da pretensão, o que significou que em $100 \%$ dos casos de judicialização houve pedido de tutela jurisdicional antecipada. O índice de sucesso foi expressivo: 69\% dos pedidos de antecipação de tutela foram deferidos. Isto é, 7 em cada 10 pedidos de medicamentos que chegaram ao Judiciário foram concedidos.

Um dado surpreendente é que a maioria das sentenças (56\%) foi proferida em até 30 dias, sendo que $1 \mathrm{em} 5$ processos receberam sentença em até 5 dias. Assim, podemos dizer que a prestação jurisdicional dos pedidos de medicamentos tende a ser bastante ágil. Tais dados problematizam a percepçáo difundida de morosidade geral da justiça no Brasil. Para os casos nos quais há uma maior demora para publicação de decisão, a principal hipótese a ser investigada se refere aos pedidos do juízo para esclarecimento quanto à possibilidade de substituição do medicamento requerido, mediante perícia ou não. No entanto, dado significativo é que $40 \%$ das sentenças não foram cumpridas pelo poder público dentro dos prazos estabelecidos.

\footnotetext{
16 Cf. DIÁRIO DE SANTA MARIA, 2015.

17 Cf. GERTNER, 2010; BIEHL, 2013; GRUDZINSKI, 2013; BIEHL; PETRYNA; AMON;
}

PICON, 2009. 
Tabela 2 - Processos judiciais referentes a medicamentos, com resolução de mérito, por tempo de espera pela decisão liminar, em 2011.

Tempo de espera

Percentual em relaçáo ao total de processos com resoluçáo de mérito

\begin{tabular}{c|c}
0 a 5 dias & $21,3 \%$ \\
5 a 10 dias & $8,8 \%$ \\
10 a 20 dias & $16,3 \%$ \\
20 a 30 dias & $10,0 \%$ \\
0 a 30 dias & $56,3 \%$ \\
30 a 60 dias & $15,0 \%$ \\
60 a 90 dias & $10,0 \%$ \\
90 a 180 dias & $10,0 \%$ \\
180 a 360 dias & $8,8 \%$ \\
\hline Média $=54,1$ dias; Mediana $=25,5$ dias &
\end{tabular}

Como mostram os referidos dados, a judicialização pode ser apenas uma fração (51\%) dos encaminhamentos dos casos; e, mesmo com um expressivo índice de sucesso judicial e com a rapidez na obtenção de decisóes, o Estado descumpre as decisóes no prazo devido em parcela significativa dos casos $(40 \%)$. Ou seja, nas demandas de medicamentos aqui analisadas, a figura do Estado aparece de forma múltipla e contraditória: (10) na origem da constituição do próprio problema jurídico (na falha em oferecer o tratamento medicamentoso adequado); (2o) no reconhecimento de uma pretensão jurídica (concretizada no pedido administrativo da medicação); (3o) na constituição do conflito jurídico (no recebimento da negativa administrativa e na formulação do pedido judicial); (4o) na conversão do conflito (da lide ou pretensão resistida) em processo judicial (no processamento da Justiça Federal); (5०) no procedimento de dizer o direito (mesmo que provisoriamente, a partir da decisão liminar); e $\left(6^{\circ}\right)$ no descumprimento da decisáo judicial (à medida que os entes federativos não cumpriram o mandado judicial de entrega da medicação no prazo estipulado). Assim, temos um caso exemplar de demonstração de que a coerência e unicidade estatal é apenas um mito, como alguns antropólogos estudiosos da burocracia apontam ${ }^{18}$.

18 Cf. HERTZFELD,1992; FASSIN, 2013; MITCHELL, 1999; SHARMA; GUPTA; 2006 


\subsection{A demanda por BPC na DPU-SM em 2011 e 2012}

Em matérias que envolvem a judicialização da seguridade social e da saúde, particularmente, a construção de dados estatisticamente confiáveis acerca das demandas e da atuação das instituiçóes públicas consiste em um instrumento cada vez mais essencial para o gerenciamento e melhoria das tomadas de decisóes ${ }^{19}$. Técnicas de estatística descritiva podem ser utilizadas como ponto de partida para a realização de diagnósticos úteis para o aprimoramento estratégico de políticas públicas, podendo ser, inclusive, compartilhadas entre instituiçóes, conferindo maior inteligência e eficiência ao sistema de proteção social e, consequentemente, contribuindo para a melhoria da qualidade dos serviços públicos e para a promoção da cidadania.

Nos resultados apresentados no relatório DPU Santa Maria em Dados, publicado no ano de 2013, verificou-se que, dentre os assistidos da instituiçáo na unidade de Santa Maria, houve um incremento significativo na demanda pelo BPC. Conforme constatado através do trabalho de mapeamento das demandas, o BPC consistiu na quarta demanda mais frequente naquele ano (somando um total de $112 \mathrm{AI}$ ), contabilizando um aumento de aproximadamente 50\%, em relação aos dois anos anteriores, na demanda dos assistidos pelo BPC.

Tendo como ponto de partida essas informaçôes preliminares e levando em conta a relevância social deste tipo de demanda, foi empreendida uma investigação mais aprofundada, objetivando se apreender os caminhos e a forma como esses atendimentos iniciais evoluíram no interior da unidade, quais foram os seus encaminhamentos, as sentenças mais recorrentes, o tempo médio de duração dos pedidos em cada etapa do processo, as razóes dos arquivamentos e as fundamentaçóes utilizadas pelos magistrados, nos casos em que a demanda foi julgada improcedente.

No biênio 2011-2012, foi registrado um montante de 149 AI em que o direito ao BPC foi pleiteado por assistidos da DPU-SM. Nesse período, o maior número de ocorrências, nesse tipo de matéria, foi identificado no mês de junho de 2011 (21 AI); por outro lado, em dezembro deste mesmo ano, assim como em fevereiro de 2012, não houve nenhum atendimento inicial registrado no PAJ como pedido de BPC. Em 2011, a média mensal de AIs em que fio pleiteado o BPC foi de 7,4; em 2012, verificou-se uma sensível retração, tendo sido contabilizada uma média de 5 atendimentos ao mês.

Desse conjunto de demandas, 70,5\% foram arquivadas pelos defensores públicos e 29,5\% foram encaminhadas para atuação judicial da DPU. Na maioria dos casos, o pedido de arquivamento decorreu em razão da ausência de retorno dos assistidos (75\% em 2011 e $54,1 \%$ em 2012). Outros motivos que fundamentaram o arquivamento das demandas foram, respectivamente: "pretensão juridicamente inviável" (10,3\% em 2011 e 18,9\% em 2012); "pretensão alcançada via administrativa" (4,4\% em 2011 e 8,1\% em 2012); "desistência explícita da pretensão" (2,9\% em 2011 e 8,1\% em 2012); "desistência da assistência da DPU em favor da nomeação de advogado particular" (1,5\% em 2011 e 5,4\% em 2012); "óbito do assistido" (nenhuma ocorrência em 2011 e 5,4\% em 2012);

19

HAIR, 2009. 
"encaminhamento a outro órgão" (4,4\% em 2011 e nenhuma ocorrência em 2012), e "PAJ duplicado" (1,5\% em 2011 e nenhuma ocorrência em 2012).

Nos casos em que o pedido de BPC foi ajuizado pela DPU-SM, durante o biênio 20112012, 11,4\% dos pedidos foram concedidos através de conciliação extrajudicial; 9,1\% foram julgados parcialmente procedentes; $20,5 \%$ foram julgados procedentes e $59,1 \%$ foram julgados improcedentes. Em quase dois terços dos casos em que a concessão do BPC foi indeferida, a fundamentação empregada pelos julgadores consistiu no apontamento de ausência de miserabilidade por parte do litigante (58,3\% em 2011 e 57,1\% em 2012). A ausência de incapacidade para trabalhar, por parte do assistido, figura como a segunda fundamentação mais frequentemente reiterada pelos juízes para o indeferimento do BPC (33,3\% em 2011 e 14,3\% em 2012). A ausência de impedimento de longo prazo não foi constatada em nenhuma sentença de indeferimento de BPC, em processos ajuizados pela DPU-SM, no ano de 2011, mas essa justificativa passou a fundamentar o indeferimento de $14,3 \%$ desses processos no ano de 2012.

Finalmente, a conjugação desses critérios (ausência de incapacidade e ausência de miserabilidade) foi identificada como razão do indeferimento em $8,3 \%$ dos casos ajuizados, em 2011, e em 7,1\% dos casos ajuizados, em 2012. A ausência de impedimento de longo prazo conjugada com o critério de miserabilidade, que em 2011 não foi motivo para o indeferimento da concessão de BPC aos assistidos da DPU-SM, fundamentou 7,1\% das sentenças de indeferimento de BPC, em 2012.

A análise desse universo de casos possibilitou a verificação de que, no biênio 2011-2012, o critério de renda (ausência de miserabilidade) consistiu em um fator particularmente relevante para a fundamentação do indeferimento de quase $70 \%$ dos pedidos de $\mathrm{BPC}$ ajuizados pela DPU-SM, ao passo que, em 30\% dos demais processos de BPC ajuizados pela unidade e indeferidos, houve a presença exclusiva de outros fatores para se fundamentar a sentença.

Outro aspecto relevante considerado na análise dos pedidos de BPC recebidos pela unidade da DPU-SM consistiu no tempo médio de espera das demandas, de acordo com a fase de atuação da instituição. É importante destacar que, entre os anos de 2011 e 2012, não se verificou nenhuma alteração significativa no tempo médio de duração desses prazos.

O tempo médio de espera entre a abertura do PAJ e a juntada dos documentos foi de 3,2 meses, em 2011, e de 3,1 meses, em 2012. De outra parte, o tempo médio de espera, a partir do momento em que a unidade da DPU-SM se encontrou em posse de todos os documentos e informaçôes do assistido - condição indispensável para o ajuizamento do processo - foi inferior a quinze dias, durante o biênio 2011-2012, especificamente, de 0,4 meses, em 2011, e de 0,8 meses, em 2012. Por sua vez, o tempo médio de espera entre o ajuizamento da ação e a publicação da sentença foi de 9,7 meses, em 2011, e de 9,6 meses, em 2012.

Em resumo, todos os processos de BPC que foram ajuizados na unidade da DPU-SM, no biênio 2011-2012, foram encaminhados e tiveram sentença proferida em menos de 14 meses. Em 2011, o tempo médio de espera entre a abertura do PAJ e a publicação da sentença foi de 13,3 meses, e, em 2012, o tempo médio de espera foi de 13,5 meses. 
Dos 149 pedidos de BPC recebidos pela DPU-SM, no biênio 2011-2012, 29,5\% - o que corresponde a um universo de aproximadamente 40 usuários do serviço - foi ajuizado pela instituição. Deste montante de açóes ajuizadas, 12,1\% teve a pretensáo alcançada pela via judicial, nesse sentido, é significativo destacar que todos esses processos, julgados procedentes, ou parcialmente procedentes, foram anteriormente negados (na via administrativa) a usuários que, conforme demonstram as sentenças proferidas pelos magistrados, efetivamente gozavam do direito de dispor desse tipo de benefício, destinado a pessoas em situação de vulnerabilidade social.

A análise desses casos evidencia a necessidade de uma reavaliação sobre a dinâmica de funcionamento do sistema de seguridade social no país. A burocratização do processo de concessão do BPC, ainda que salutar quando focada em evitar fraudes, resulta também, em muitos casos, na violação de direitos de pessoas que são o público-alvo de políticas desta natureza. Acerca disso, a produção de estatísticas relacionadas à atuação da Defensoria Pública (em todos os seus graus de organização) pode colaborar para o aprimoramento e a modernização na gestão estratégica de políticas públicas.

Além disso, a análise dos dados coletados evidencia que a atuação da DPU-SM, em matérias dessa natureza, tem sido relativamente célere. $\mathrm{O}$ tempo médio de espera do usuário do serviço costuma ser dilatado sobretudo em razão da demora por parte dos assistidos em conseguir obter toda a documentação necessária (tempo médio de espera de 3 meses) para dar início ao processo judicial; de outro lado, verifica-se que a média mais alta no tempo de espera resulta da morosidade do sistema de justiça, que não levou menos de nove meses para proferir uma sentença neste tipo de matéria em nenhum dos casos examinados.

Por fim, ao realizar uma triagem acerca dos casos que realmente necessitam ser encaminhados à via judicial, através do arquivamento de demandas que, conforme análise de defensores públicos, de antemão, são identificadas como improcedentes, a DPU (na qualidade de instituição essencial à função jurisdicional do Estado) contribui ao priorizar a atuação extrajudicial, evitando o agravamento do quadro de engarrafamento de processos judiciais na justiça brasileira.

\subsection{A demanda por cirurgias na DPU-SM em 2015}

Como já referido anteriormente, os atendimentos iniciais na DPU-SM referentes à categoria "saúde" constituem proporção expressiva do total dos atendimentos realizados. Isso se dá devido à ineficiência do Estado em fornecer a adequada assistência a toda população. Como já mencionado, nos últimos anos houve um decréscimo dos pedidos por medicamentos, talvez por haver um maior fornecimento administrativo das substâncias pleiteadas; mas, em contrapartida, houve um crescimento no número de atendimentos referentes a procedimentos cirúrgicos. A judicialização da saúde assume contornos bastante específicos no contexto local de Santa Maria (e da região central do Rio Grande do Sul, por extensão), no qual a insuficiente capacidade de instituiçóes como a $4^{\text {a }}$ Coordenadoria Regional de Saúde (4ª CRS) e o Hospital Universitário de Santa Maria (HUSM) em darem conta da demanda regional por acesso à saúde emerge como uma variável 
potencialmente explicativa.

No ano de 2015, 29,7\% do total dos PAJs abertos na DPU-SM correspondiam a demandas relacionadas à saúde, configurando-se essa a matéria predominante nos atendimentos da unidade. Atrás dela, ficaram as demandas previdenciárias, com $25 \%$ do total dos PAJs, seguido por cíveis em geral (22\%), penais (11\%) e penal militar (7\%). Inclusos na categoria "Cível Saúde" estão os pedidos de cirurgia, medicamentos, equipamentos e materiais, internação, tratamento, exame, consulta e outros ${ }^{20}$. A categoria respondia, em 2015, por mais de um terço dos PAJs instaurados, superando demandas previdenciárias e matérias cíveis de outras naturezas.

Nesse universo de PAJs "Cíveis-Saúde", verificou-se em 44,9\% deles a pretensão/necessidade do assistido de ser submetido a algum tipo de cirurgia, o que corresponde a 13,1\% do total de atendimentos realizados no ano de 2015 na DPU-SM. Nesse sentido, destacam-se os pedidos de cirurgias traumato-ortopédicas, as quais correspondem a $61,8 \%$ dos requerimentos de cirurgia. Esse valor é bastante significativo se comparado às proporçóes dos demais tipos de cirurgias requeridos, quais sejam: oftalmológicas (14,5\%), gerais, oncológicas e gastroentorológicas $(7,3 \%$ cada) e pediátricas $(1,8 \%)$. Além desses, houve a judicializaçáo de 5 PAJs classificados na categoria "equipamentos e materiais" que também envolviam cirurgias traumatológicas. Assim, foram 39 as demandas judicializadas envolvendo cirurgias traumato-ortopédicas em 2015.

Nesse ano, percebeu-se que menos da metade das demandas de saúde em geral é judicializada, embora o índice de judicializaçáo dos pedidos de medicamentos tenha se aproximado do dobro do registrado nos pedidos de cirurgia. Quanto ao tempo de tramitação interna das demandas de saúde, os dados indicam - provavelmente pela maior dificuldade de obtenção de consultas e laudo - que o tempo médio de entrega da documentação completa nos casos de cirurgia é cinco vezes maior do que nos pedidos de medicamentos. Enquanto a média de dias entre o atendimento inicial e a conclusão da documentação pelo assistido em pedidos de medicamentos foi 9,4 , nos casos de cirurgia o número chegou a 49,6 .

Nas demandas de cirurgia, em relação aos dias decorrentes entre o primeiro atendimento e o ajuizamento da ação, a média foi de 73,5 e, até a prolação de decisão judicial a média foi de 208,6 dias. Ou seja, comparando-se com os casos de pedido de medicamentos, a resolução das demandas de cirurgia é muito mais morosa, tanto no processamento interno da DPU-SM (atendimento inicial, recolhimento de documentos, análise do caso, elaboração da petição inicial, ajuizamento) quanto no desenvolver do processo judicial. Isso pode ser explicado pela dificuldade dos assistidos em conseguir atestados que comprovem a necessidade e a urgência da cirurgia e também por alguns entraves impostos pela Justiça, como intimação do HUSM para dizer sobre a possibilidade de realização da cirurgia naquele hospital, pedidos de atestados mais específicos e determinaçóes de perícias judiciais.

20 Em "outros" incluem-se demandas diversas que não se enquadram em nenhuma das categorias pré-definidas, como pedido de acompanhamento diário de profissional de enfermagem na residência do assistido devido a impossibilidade da família em fornecer os cuidados necessários, ou pedido de tratamento odontológico, por exemplo. 
Quanto ao sentido das decisóes judiciais relativas aos pedidos de cirurgia, verificou-se que $8 \%$ das demandas foram extintas sem resolução do mérito, 34,7\% foram julgadas procedentes, $13,3 \%$ improcedentes e $44 \%$ estavam pendentes de decisão quando da coleta dos dados.

Como referido acima, as demandas de cirurgias traumato-ortopédicas aparecem como um caso limite e emblemático desse quadro crítico que se reflete cada vez mais na busca de assistência jurídica gratuita como mediação para a luta pela garantia de direitos. Verificou-se que a patologia mais frequente nesses casos é coxartrose, seguida por casos de ruptura de tendôes e fraturas. Dessa forma, consequentemente, o procedimento mais pleiteado é o de artroplastia ou revisóes de artroplastia, com um percentual de 38,5\% do total dos pedidos de cirurgia.

Para ilustrar essa situação, pode-se trazer o caso de um agricultor de 51 anos, diagnosticado com coxartrose de quadril esquerdo. Ele necessitava de uma artroplastia total coxofemoral esquerda e, quando compareceu ao atendimento da DPU-SM, em 30/06/2015, estava há dois anos aguardando na fila de espera do SUS. Em decorrência da enfermidade, estava há três anos sem poder trabalhar, recebendo auxílio-doença, já que essa condição de saúde implica em muita dor e dificuldade em deambular. A sentença de procedência foi prolatada em 29/03/2016 e, no momento da coleta dos dados, a cirurgia ainda não havia sido realizada, estando pendente do recebimento de orçamentos de hospitais particulares.

$\mathrm{Na}$ análise das decisóes das demandas de cirurgias traumato-ortopédicas judicializadas pela DPU-SM, verifica-se que o resultado do pedido de antecipação de tutela em 14\% dos casos foi procedente; em $27,9 \%$ deles, foi improcedente; e em 58,1\%, estava pendente de apreciação. Observou-se que em $75 \%$ dos casos de indeferimento o embasamento da decisão era a não constatação de urgência na realização do procedimento cirúrgico. Já em relação ao resultado da sentença final, em 33,3\% dos casos o pedido foi considerado procedente; em $2,6 \%$, improcedente; em $20,5 \%$, a ação foi extinta sem resolução do mérito; e em $43,6 \%$ estava pendente de decisão quando da coleta dos dados.

Cabe destaque, aqui, o número significativo de açóes extintas sem resolução do mérito. Foi observado durante a análise dos PAJs que, nos casos de pedido de cirurgia, muitas vezes não havia uma decisão específica deferindo ou indeferindo a antecipação de tutela. Era comum o juízo, logo após a ação ter sido protocolada, requerer a intimação da direção do HUSM para que informasse se o hospital dispunha das condiçóes necessárias para realizar o procedimento requerido, sob a justificativa da necessidade de esgotarem-se todas as possibilidades de resolução do caso na via administrativa antes de prolatar decisão judicial que forçasse o poder público a disponibilizar o procedimento ou arcar com seus custos em hospital particular.

Disso decorria que, em numerosos casos, a cirurgia era realizada no transcorrer da ação, mas sem um deferimento efetivo do pedido, e, quando do momento da prolação da sentença, o juízo decidia por extinguir o feito sem resolução do mérito aduzindo a perda do objeto da ação. A consequência prática desse tipo de decisão é a não determinação de honorários em favor da DPU-SM, prejudicando, assim, a instituição. Importante frisar que essa prática do juízo é questionável, uma vez que, em realidade, os pedidos de cirurgia só se concretizaram em razão da intervenção do Judiciário, apesar de não ter havido uma 
decisão procedente propriamente $\operatorname{dita}^{21}$.

Por fim, é interessante trazer dados relativos à efetiva realização das cirurgias traumato-ortopédicas pleiteadas. Na ocasião da coleta dos dados, $41 \%$ dos pedidos tinham sido efetivados, $15,4 \%$ não e $41 \%$ ainda estava pendente de realização, e havia uma cirurgia agendada para ocorrer em breve. Quanto aos locais onde são realizadas essas cirurgias, 68,8\% ocorreram no HUSM, 18,8\% no Hospital São Francisco de Assis (HSFA) e 12,5\% em hospitais fora do município.

\section{CONSIDERAÇÓES FINAIS}

Por meio do "DPU SM em Dados", ao longo dos últimos anos, a análise de demandas permitiu lançar luzes sobre a efetiva atuação do núcleo da DPU-SM. Além disso, possibilitou a identificação de pretensóes sub-representadas ou super-representadas - demandas que supostamente são mais frequentes no cotidiano da população socialmente vulnerável do que se evidencia estatisticamente, ou mesmo que se encontrem em um pico de litigiosidade. Em ambos os casos, abre-se a possibilidade de políticas institucionais: no primeiro, por meio de estratégias de administração e solução das demandas; no segundo, através da promoção do acesso à justiça mediante a ampliação de iniciativas de difusão do conhecimento sobre direitos e da expansão dos atendimentos da DPU externos ao núcleo.

Observada mesmo nos três diagnósticos promovidos pelo Ministério da Justiça acerca da Defensoria Pública no Brasil (BRASIL, 2005, 2006, 2009), a carência da produção sistemática e rigorosa de pesquisas locais e nacionais sobre os destinatários da assistência jurídica evidencia que a instituição ainda pouco conhece seu público. Deixar de produzir esse conhecimento, tão pertinente ao olhar das ciências sociais, significaria um distanciamento da instituição em relação à promoção, de forma coordenada, da ampliação e da qualificação de seu atendimento, da transparência de sua atuação, da abertura às demandas sociais emergentes e da eficácia de seus projetos institucionais ao longo de todo o ciclo de realização. Portanto, a realizaçáo do perfil dos assistidos tem por objetivo conhecer o alcance do cumprimento de seu papel democrático, à medida que torna possível avaliar se a DPU não tem conseguido atingir as parcelas socialmente vulneráveis da população.

As conclusões da presente pesquisa confirmam que ainda há um longo caminho no sentido da universalização do acesso à justiça. Afinal, há indícios de que as camadas da populaçáo que se encontram em situação de maior vulnerabilidade social (como aqueles em extrema pobreza) pouco têm acesso ao conhecimento sobre direitos e sobre a existência da

\footnotetext{
$21 \quad$ Pode-se citar como exemplo desse tipo de decisão o caso de uma assistida que necessitava de cirurgia no ombro. O procedimento pleiteado foi realizado no decorrer da ação e, no momento da sentença, o juízo extinguiu o feito sem resolução do mérito, como se observa no trecho transcrito abaixo:

"Nesse sentido, "o interesse do autor deve existir no momento em que a sentença é proferida. Se desapareceu antes, a ação terá de ser rejeitada, de ofício e a qualquer tempo" (3a Turma do STJ, REsp 23.563 -RJ -AgRg, rel Min. Eduardo Ribeiro, DJU 15.09.97). Destarte, realizada a cirurgia vindicada pela Autora, ocorreu a perda do interesse processual, razáo pela qual deve ser extinta a demanda, sem a análise do mérito. Ante o exposto, julgo extinto o processo sem resolução do mérito (...) Custas e honorários advocatícios incabíveis na espécie (...)"
} 
DPU. Por outro lado, no último levantamento de dados quanto ao perfil dos assistidos, relativos a 2016, não se confirmaram ${ }^{22}$ as tendências de relativa feminização, envelhecimento e aumento da renda média familiar, apontadas em trabalho anterior ${ }^{23}$.

Os dados da DPU-SM em Santa Maria acerca das demandas recebidas corroboram a constatação de aprofundamento do vínculo entre o jurídico e a gestão da saúde pública, bem como a afirmação de que boa parte da atuação das instituições jurídicas em assuntos relativos à seguridade social é extrajudicial. Tais conclusóes são corroboradas pelas pesquisas específicas sobre medicamentos, benefícios de prestação continuada e cirurgia, as quais evidenciam fatores que impactam decisivamente na satisfação eficaz das pretensóes dos assistidos. Exemplos disso são as eventuais necessidades de perícia, de juntada de documentos adicionais (e.g. laudos e orçamentos) e de fiscalização do cumprimento de decisóes judiciais, frequentemente descumpridas a tempo pelo próprio Estado.

O desenvolvimento de iniciativas de atendimento, divulgação institucional e promoção de direitos para fora do núcleo (como o "DPU Itinerante", "DPU na Comunidade"24 e o "DPU nas Escolas" 25 - todos eles informados pelos resultados obtidos no projeto "DPU SM em Dados" -) tem rendido frutos importantes em termos de difusáo da assistência

\footnotetext{
22 A continuidade da realização da pesquisa permitirá uma melhor avaliação das tendências de mudanças no perfil de assistidos.

23 PEDRETE, 2016.

24 Destinado a levar o atendimento da DPU a localidades em situação de risco social, o projeto foi implementado pela unidade em 2011, quando foram realizadas parcerias com os três centros de referência em assistência social de Santa Maria (CRAS Norte, CRAS Oeste e CRAS Leste), tendo sido contemplados 3 bairros (Camobi, Chácara das Flores e Nova Santa Marta). A partir de 2012, com a observada queda do número de atendimentos, decidiu-se por modificar a natureza da atuação do projeto. Em vez de priorizar-se o atendimento ao público socialmente vulnerável dos bairros de Santa Maria, preferiu-se a realização de eventos de promoção dos direitos e difusão dos serviços da DPU. Assim, a DPU participou da inauguração da nova sede do CRAS Leste e promoveu duas palestras para a população em situação de rua na Casa de Passagem de Santa Maria. Além disso, o núcleo promove anualmente atendimentos ao público na praça Saldanha Marinho por ocasião do dia Nacional da Defensoria e participou do "Mutirão da Cidadania”, onde - ao lado de instituiçóes como Defensoria Pública do Estado, PROCON, INSS e Receita Federal -realizou dezenas de atendimentos. Desde 2016, o núcleo passou a promover ainda o "Multiplicadores de Direitos", projeto desenvolvido pela equipe multidisciplinar da unidade da DPU Porto Alegre-RS, por meio das quais serão realizados eventos de capacitação e troca de experiências junto a profissionais da rede de proteção social, tais como assistentes sociais e psicólogos(as).

25 Entre o segundo semestre de 2013 e o primeiro semestre de 2014, houve o planejamento e execução de uma experiência piloto do projeto na Escola Estadual de Ensino Básico Augusto Ruschi, localizada na COHAB Santa Marta, no bairro Juscelino Kubitschek, um dos quatro com menor índice de renda e instrução no município, e um dos dois com maiores taxas de ocorrências de tráfico, roubos, furtos, agressóes e homicídios, além de ser marcado por carências de infraestrutura. A execução do projeto de pautou pela tentativa de sensibilização dos agentes envolvidos para a luta pela cidadania e esclarecimento jurídico de forma significativa, priorizando o vínculo com a vivência de problemas cotidianos, a participação emancipatória dos atores envolvidos e a abertura ao reconhecimento de suas demandas. Por isso, o projeto não foi limitado à realização de palestras ou concursos de redação. Ele incluiu o estímulo dos professores à narração das histórias dos alunos por eles mesmos, a realização de palestras de uma apresentaçáo sobre direitos com espaço para depoimentos pessoais dos educandos. Numa segunda visita, houve a apresentação dos resultados da atividade "Turma Cidadâ" - com o objetivo de transformar os alunos em multiplicadores das informaçôes sobre os serviços oferecidos pela DPU, cada aluno foi incentivado a investigar, dentre seus familiares, conhecidos e vizinhos, possíveis demandas ou dúvidas relacionadas a direitos. Cada turma trabalhada ficou responsável pela elaboração de um relatório da experiência de campo, contendo uma lista das demandas registradas.
} 
jurídica integral e gratuita desta Defensoria. Como já salientado em outro trabalho ${ }^{26}$, observa-se um efeito de retroalimentação entre o projeto DPU/SM em Dados e os projetos especiais desenvolvidos no núcleo da DPU em Santa Maria-RS. A focalizaçáa do atendimento em grupos vulneráveis, a desconcentração territorial do atendimento e uma maior atenção à atuação preventiva/consultiva resultaram em açôes institucionais efetivas.

Diante do exposto, não restam dúvidas de que a produção de conhecimento sobre as demandas e seus agentes é indispensável para uma avaliação precisa do grau de efetividade desta instituição no cumprimento de sua missão de garantir aos necessitados o conhecimento e a defesa de seus direitos, e firmar-se como instrumento de transformação social.

\section{REFERÊNCIAS}

BIEHL, J. (2013) "The judicialization of biopolitics: Claiming the right to pharmaceuticals in Brazilian courts”. American Ethnologist, 40: 419.

BIEHL, J.; PETRYNA, A.; AMON, J.; PICON, P.; (2009) “Judicialisation and the Right to Health in Brazil." The Lancet, 2009, 373: 2182-84.

BRASIL. Defensoria Pública da União (2012) Plano estratégico da Defensoria Pública da Uniāo: 2012-2015. Brasília: DPU

BRASIL. Lei no 12.527 , de 18 de novembro de 2011.

BRASIL. MINISTÉRIO DA JUSTIÇA (2005), I Diagnóstico da Defensoria Pública no Brasil. Brasília.

Brasília

(2006), II Diagnóstico da Defensoria Pública no Brasil.

Brasília.

(2009), III Diagnóstico da Defensoria Pública no Brasil.

CAMPOS, A.M. (1990)“Accountability: quando poderemos traduzi-la para o português?” in: Revista de Administração Pública, Rio de Janeiro, fev./abr.

DIÁRIO DE SANTA MARIA (2015) “Servidor público é preso por suspeita de superfaturar medicamentos em Santa Maria”. Disponível em: http://diariodesantamaria. clicrbs.com.br/rs/geral-policia/noticia/2015/03/servidor-publico-e-preso-por-suspeitade-superfaturar-medicamentos-em-santa-maria-4726732.html Acesso em:28 jul. 2016

FASSIN, D. (Org.) (2013). Juger, Réprimer, Accompagner. Essai sur la Morale de l'Eat. Paris, Éditions du Seuil.

GERTNER, A.K. (2010) Pharmaceutical care, public experiments and patient

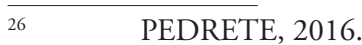


knowledge in the Brazilian Public Healthcare System. 147 f. 2010. Monografia (graduaçâo em Antropologia). - Universidade de Princeton. Nova Iorque.

GRUDZINSKI, R. (2013). A nossa batalha é fazer o governo trabalhar: estudo etnográfico acerca das práticas de governo em uma Associação de Pacientes. Dissertaçáo (Mestrado em Mestrado em Antropologia Social) - Universidade Federal do Rio Grande do Sul

HAIR, Joseph F. et al. Análise multivariada de dados. Porto Alegre: Bookman, 2009.

HERZFELD, Michael. 1992 - The social production of indiference. Exploring the symbolic roots of Western bureaucracy. Chicago and London: The University of Chicago Press, 1992

MITCHELL, T. (1999). "Society, economy and the state effect". In: Steinmetz, George (ed.). State/Culture. State-formation after the cultural turn. New York: Cornell University Press, 1999. p.76-97

NONET, P. \& SELZNICK, P. (2001). Law and Society in Transition. New Brunswick : Transaction

PEDRETE, L.A (2016).”Por uma abordagem das práticas de acesso à justiça no universo da Defensoria Pública da União: contribuiçōes sociológicas" in: A Defensoria Pública da União e o Acesso à Justiça. Coletânea Acesso à Justiça. Brasília.

PINHO, J.A.G.; SACRAMENTO, A.R.S..(2009) "Accountability: já podemos traduzi-la para o português?” in: Revista de Administração Pública., vol.43, n.6 , pp. 1343-1368

SADEK, M. T (2008). A Defensoria Pública no Sistema de Justiça Brasileiro. APADEP em Notícias, São Paulo, 30 jul. 2008.

SANTOS, B. de S. (2007), Para uma revoluçáo democrática da justiça. São Paulo: Cortez.

SELZNICK, P (1969) Law, Society, and Industrial Justice. Russell Sage Foundation, New York.

TATE, N; VALLINDER, T. (1995) (eds). The Global Expansion of Judicial Power. New York, London: New York University. Press. 